\title{
ARGUMENTATIVE POWER: A Critical Discourse Analysis for Academic Purpose
}

\author{
Nur Najibah Sukmawati, Sukma Septian Nasution \\ Universitas Pamulang \\ Email: dosen01859@unpam.ac.id
}

\begin{abstract}
A text deserves comprehensive analyses on its textual structure as well as socio-cultural context to meet readers' comprehension. This paper aims at (1) finding out linguistic styles of the texts and (2) identifying power struggle behind an argumentative text entitled Computer for Children: Advantages or Drawbacks? used to the third students of Informatics Engineering Department at a private university in South Tangerang, Indonesia as a material in learning argumentative text. This is a critical discourse analysis by using Fairclough's model which consists of description, interpretation, and explanation. In analyzing the text, systemic functional linguistics is used to find out the texts' power as well as to determine whether the texts are adoptable for the students to learn argumentative texts. The analysis concludes that (1) formal, complex, verbal, repetitive, multi-perspective, evident-based, metaphorical, and over-wording dictions underpinned in an institutionalized social activity and unspecialized semantic domain dominate the texts which conclude that (2) its power to the readers is all equal that the author provoked rather than provided, evident-based and analytical arguments of the issue.
\end{abstract}

Keywords: argumentative text, critical discourse analysis,

\section{INTRODUCTION}

Implicit elements of a text are sometimes more important to understand than what is stated explicitly. However, many people invest significant effort in comprehending a text through linguistic unit. They focus on analyzing the meaning conveyed by its syntactical chains. Understanding syntactical chains realized by clauses makes the readers ignore meaning behind its text which is potential to explore to find out more information of the text.
Consequently, intended ideas of the text cannot be comprehended completely. This is why criticizing elements behind the text is necessarily significant to make us a critical reader.

A critical reader comprehends a text as a coherent way of making sense of and constitutes the world (Locke, 2004) which states contextual configuration (Hasan in Lukin, 2017) beyond its syntactical chains and paragraphs' interrelatedness. Understanding text means understanding elements 
beyond grammar (Knapp, and Watkins, 2005) that if criticized, will bring the reader to contextually broader information (Lukin, 2017). Further, text is dependent on context that as an analytical construct that emerges articulation of moments, text and context are inherent (Saragih, 2010) where text is meant as a system of communication organized as cohesive unit (Knapp and Watkins, 2005) that is generated by context (Locke, 2004). Context is, on the other hand, viewed as socio-cultural values that can be found in a text.

One of interesting exploration to a text is how language is a representative to show power of the author(s). Acknowledging the author's power enables readers to be more critical in deciding postreading attitude. This paper aims at (1) finding out the relation of language and power in three selected authentic texts used as a material to teach writing to the third semester students of Informatics Engineering in a private university, and (2) deciding whether the texts are acceptable to be adopted as materials for the students to learn argumentative text.

In analyzing the meaning behind the text, systematical procedure of analysis is necessarily needed. One of popular means of critical discourse analysis is introduced by Fairclough (1989) that divides a text into three. They are description, interpretation, and explanation. Description is a linguistic layer that analyzes a text based on its diction, unity of some diction, until syntactical chain that forms a clause. Interpretation analyzes situational and cultural context of the text. Explanation step concerns with ideology that is related to sharedknowledge between the author(s) and the readers.

In doing such analysis and categorization of each layer, systemic functional linguistics (SFL) is used. For SFL, text is a system of meanings. That is to say when people use language, their language acts produce or construct meaning (Bloor and Bloor, 2004). CDA by SFL enables us to look into the discourse dimension of power abuse, which leads to injustice and inequality. The text analyzed in this study is modified from debatabase $\sigma^{\text {th }}$ edition used as to teach argumentative text to the third semester students of Informatics Engineering Department of a private university in South Tangerang, Indonesia as shown by Figure 1 .

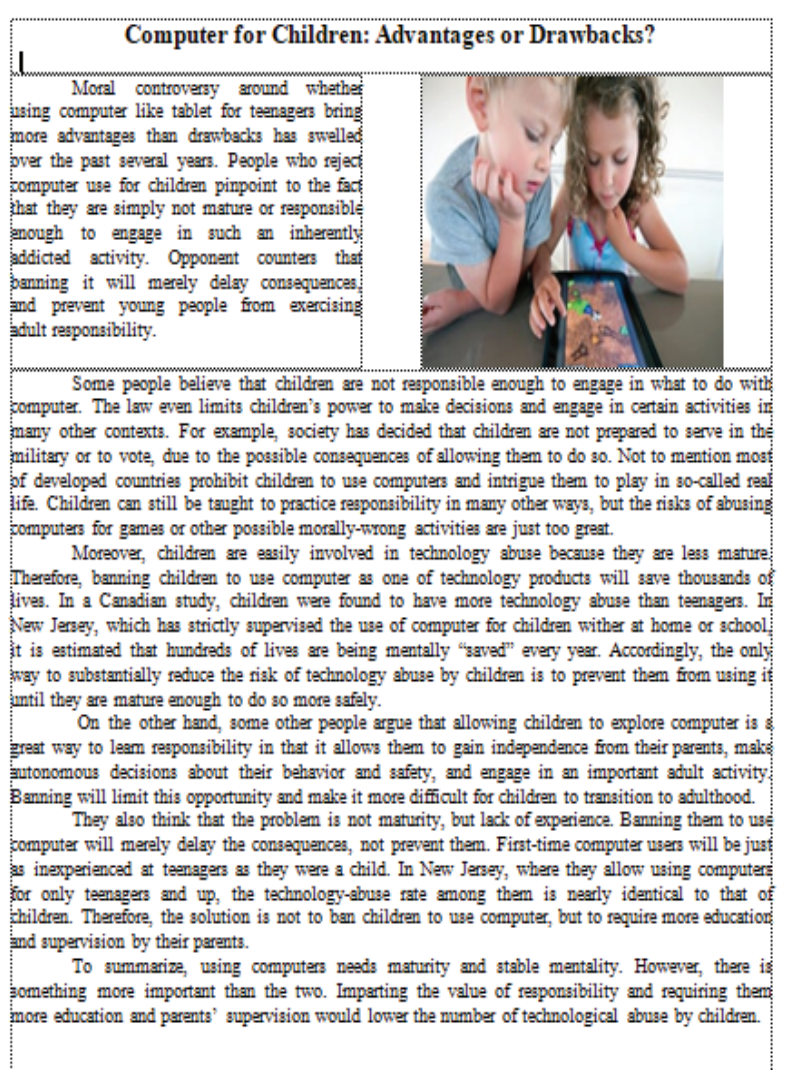

Figure 1. The Material 
The author of the text provides equal and balanced arguments on whether using computer brings more advantages than drawbacks for children. As one of the essential functions of text is to persuade others to one's point of view, it is possible to analyze the linguistic structures and the discursive strategies of a discourse in order to uncover the power struggle, social inequality, and other forms of social and political problems at issue (Dijk, 2008). CDA accounts for how discourse structures - which are established through various linguistic patterns and structures - work in their specific ways to convey social cognitions (how people think) - which in turn, contribute to the development of the social strictures of inequality and injustice of power in society (Flowerdew, 2013).

Some mainstreams in CDA were shown in the following studies: First, a study by Patient Rambe (2012) entitled critical discourse analysis of collaborative engagement in Facebook paintings aims at exploring academic relations of social networking sites (SNSs) and relational power of micro level, particularly university as an educational body. Using CDA and educators-learners Facebook conversation to expose the exercise of relational power and social learning, this study finds that the prevalence of formal authoritative (or hierarchical) discourses, few informal liberating discourses, nascent peerbased collaboration and limited learner engagement with theory. These phenomena generally point at first year students' under-developed study skills and less sophisticated literacies. This study is related to extent of using CDA as a main tool of analysis. The difference is that the aim is to explore the impact of the SNSs conversation, but my paper focuses on power hidden in the text.

Second, Nova Anggit Priatmoko (2013) in his study entitled critical discourse analysis of the speech of Susilo Bambang Yudhoyono aims at describing language, power, and ideology of SBY's speech about the Jakarta bombings. The analysis of this thesis published by Universitas Dian Nuswantoro of Semarang is based on theory of CDA and its analysis methods presented by Thomas N.Huckin. The finding shows that through the language used, it can be known the strength of power and the purpose of the speaker, which the power is strongly felt and the ideology is clearly seen as well as understandable. This study is related to the extent of topic areas where the use of CDA to explore language, power, and ideology is employed. The difference lies on the subject being analyzed. My subject is an authentic written text, but this study analyzed a speech.

The third related study is from Nasir. H.S. Bukhari, and Wang Xiaoyang of Institute of Education Tsinghua University, Beijing,China. The study conducted in 2013 aims at reviewing the literature related to CDA and its development and to find the answer of the question whether we could use CDA in educational. By using historical descriptive research methodology, this study finds that CDA is an emerging approach and methodology that has successfully attracted the attention of researchers interested in carrying out research on the relationship between superstructures and social issues. This study is related to the extent of CDA as a means of analysis but only focuses on exploring its potentials to be used in educational research. On the other hand, 
my study focuses on the implementation of CDA to explore hidden power in a text.

Comparing two articles in terms of opinion quality is conducted by Stefan Thomson who was gaining his master degree at Birmingham University, 2007. He compared the two articles published by the Daily Mail, a United Kingdom-based media, and Korea Herald, a local Korea media, discussing similar topic: outbreaks of food and mouth disease and H5N1 Avian flu in South Korea by using critical discourse analysis. This study finds that The Daily Mail article represented the events from a highly negative perspective. It used strong vocabulary and sources opposed to the measures to add opinion to an article that is portrayed as 'hard news'. On the other hand, The Korea Herald sought to allay public concerns. Its article mentioned few of the negative aspects of the story, or at least referred to them obliquely to show the situation in a better light. Its sources were attributed exclusively to government officials. This meant that the information was restricted only to that which the government wanted to be present. This study is related to the extent of finding out hidden agenda of a text. The difference is if my paper explores one article from similar perspective, Thomson compare two texts.

\section{FINDINGS AND DISCUSSION}

The technique of analyzing the discourse is by using Norman Fairclough's model of critical discourse analysis. Fairclough's model has three subanalysis headings: description, interpretation, and explanation where each heading is, then, analyzed by using systemic functional linguistics. The analysis of the text is critically elaborated as follows:

\section{Description}

Vocabulary used in the text can be used as a way of analyzing language structure shown as follows: Firstly, the text has both positive and negative classification scheme. Words such as irresponsible, not prepared, strictly, risk, and less mature are words possessing negative value. In contrast, the words like great, independence, safety, responsible are to positive value. Table 1 shows the dictions and their position in the text.

Table 1. The Positive and Negative Dictions

\begin{tabular}{|c|c|c|}
\hline \multirow{2}{*}{ Paragraph } & \multicolumn{2}{|c|}{ Dictions } \\
\hline & Positive & Negative \\
\hline 1 & - & $\begin{array}{l}\text { immature, irre- } \\
\text { sponsible }\end{array}$ \\
\hline 2 & - & $\begin{array}{l}\text { Irresponsible, } \\
\text { morally-wrong, } \\
\text { strictly }\end{array}$ \\
\hline 3 & - & $\begin{array}{l}\text { Less mature, tech- } \\
\text { nology abuse, }\end{array}$ \\
\hline 4 & $\begin{array}{l}\text { Great, indepen- } \\
\text { dence, autono- } \\
\text { mous decision, } \\
\text { safety }\end{array}$ & Limit, difficult \\
\hline 5 & - & $\begin{array}{l}\text { Lack of experience, } \\
\text { delay, inexperi- } \\
\text { enced, }\end{array}$ \\
\hline 6 & $\begin{array}{l}\text { Good, maturity, } \\
\text { stable mentality, } \\
\text { important }\end{array}$ & $\begin{array}{l}\text { Technological } \\
\text { abuse }\end{array}$ \\
\hline
\end{tabular}

To be seen in detail, position of the negative values is different from that of positive values in the text. Negative dictions are mostly employed in 
the second and third paragraphs which are actually arguments contradicting the issue. The reason why the negative choices are used is to struggle the contradicting arguments' power argued by opponents that negative effects of allowing the 16 year olds driving are caused by their negative attitudes such as irresponsible, less prepared, and less mature. It is in line with Jiao, and Zhou (2011) that negative opinion words are used to identify sentiment polarity. In contrast, the positive value of dictions like great, independence, safety, and responsible are chosen to signify the position of supporting the issue to allow them to drive legally. The matter of independence, learning to be responsible, great challenge to be mature, and so on are mostly used as arguments to support the issue because the author would like to strengthen pros' power of why the issue needs to be supported. This is supported by Trabelsi, and Zaiane (2014) that dictions which pinpoint endorsement such as great, good, well are lexically voices of the same stances of argument.

This analysis reveals that the existence of negative and positive value is likely balanced. This is to show that the author struggles to be neutral in responding to the issue. This is in line with definition of Knapp and Watkins (2005) that discussion is a more sophisticated argument as it involves the consideration of an issue from a number of perspectives.

Secondly, the process happening in the text is dominated by mental process. It is a process which involves phenomena best described as states of minds or psychological events (Bloor and Bloor, 2004). Further, mental activities found in the text are believe, think, consider, etc.. The sense, the participant doing the mental process, in the text is characterized impersonally such as it is believed that or to be common people like many people believe that. As the phenomena are realized in form of argument plus evidence, so the choice of mental process in discussion text is unmarked or acceptable. It is supported by that Bloor and Bloor (2004) that mental process is to portray how people build their argument in spoken and written form.

Thirdly, there are many words which appeared more than once. They are mature and maturity, responsible and responsibility, children, computer, and engage (2 times) as seen in Figure 2.

Figure 2. The Frequently-Used Words

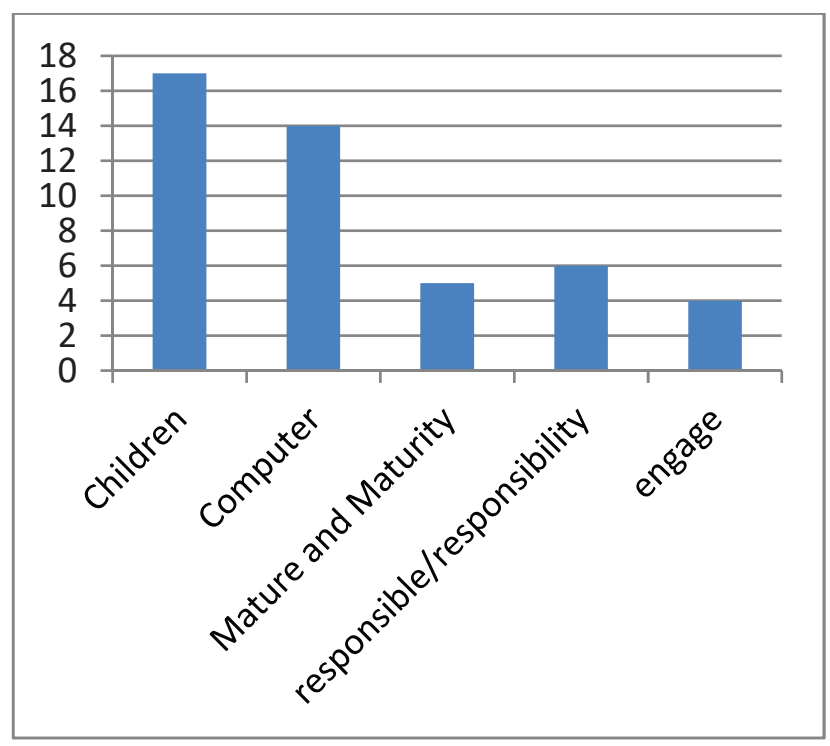

The reason why these words appear more frequently is because the author wants to show that the major contention about the issue whether children should or should not have exposure on computers because they are mature or not, and responsible or not and why they should or should 
not engage with it. The author would like to direct the readers to focus on the afore-mentioned points only and to ease the readers to predict about what the contentions are all about. It is in line with a finding by Locke (2004) that repetition is used to emphasize high level of constituency.

Fourthly, over-wordings are also found in this text. They are has swelled, the leading cause, and increase, thousands of life. The sentence therefore, banning children to use computer as one of technology products will save thousands of lives is over-wording. How could banning children using computer save thousands of lives effectively? By such expression, the author actually aimed to emphasize the importance of banning computer use for children so it is expected that the readers will be emotionally influenced to the argument. This is the way how the author makes the struggle for power from negative side or those who contradict the issue. The author also shows the power of positive side of the issue through this sentence on the other hand, some other people argue that allowing children to explore computer is a great way to learn responsibility in that it allows them to gain independence from their parents, make autonomous decisions about their behavior and safety, and engage in an important adult activity. The use of over-wording strategy in this part is as the way the author struggles to empower the position of positive side to the issue to make the arguments sound meaningful and strong (Kristina, 2014).

Fifthly, it can be ideologically said that the meaning which appears most is antonym. It is plausible because in discussion text, contradiction often occurs between two dissenting groups and to show how they contradict each other, they need to encounter the opponents' statement. One of the ways to encounter is by using antonym. It is supported by Syarifah and Gunawan (2015) that hat the social function of discussion text is to discuss an issue from different point of view which is signaled by argument for and argument against the topic.

Finally, the uses of metaphorical subject like some people believe that, they also think that, and so on. These are used as a way to be free of any responsibility to have uttered the argument. It is realized from many people, some people and they which are chosen. It means it is not only he/she uttering so but other people do: there are more than one resource.

\section{The Relational Aspects}

Relational aspect refers to social relation between the readers and the author. The relational aspect of the text is equal relation instead of hierarchical one. It can be seen from the absence of imperative words. Instead of instructing or commanding, both pro and contra arguments use modality such as would. This modality choice is meant to suggest, to influence but not to instruct. The would choice in this sentence is employed to influence the readers: Imparting the value of responsibility and requiring them more education and parents' supervision would lower the number of technological abuse by children. Influencing activity is common to be used in discussion text. It is given to those who have equal position to the speaker/writer. The equal relation is chosen because the purpose of the text is to discuss the issue between the author and the readers. Usually, those who are involved in a discussion are considered to have equal knowledge or ability in discussing and altogether, solve the problem 
so they are respectively equal. In this case, the author is not in the capacity of influencing the readers to follow his/her way of thinking rather than to show the readers advantages and drawbacks that children can face once they are involved in computer-based activities.

This text also employs many logical connectors/ cohesion. Because, therefore, accordingly, to prove are to mention some.. The logical connectors/cohesions are used to signify the logic of the statement, to show cause-and-effect relationship, and to conclude (Leech, 2000). This is to help and improve the intelligibility of the text as well as an effort from the author to arrange the arguments from both sides sound logic and acceptable. The more it sounds logic, the more it makes sense to the readers. In short, the author struggles all arguments to be logically acceptable. This is in line with Santosa (2011) that logical connectors are part of textual element which is used to organize and synchronize one to another idea.

In syntactical level, majority of the sentences in the text is not simple sentence by type rather than in form of complex sentence. Such sentences are the typical of written text instead of spoken text (McCarty, and Carter, 2001). It is found that all types of sentence are used in the text. They are four simple sentences as well as compound sentences found in the text. Further, there are five compound-complex sentences. And there are 10 complex sentences found. This complex syntactical chain is plausible because the author understand that this text will be consumed by adults who already have capacity to understand complex and compound sentences. The text is rarely in simple sentence because this is not meant to be consumed by children who will find it hard to understand. Nasution (2018) states that one of language styles adult use is sentences they produce is in form of complex sentence. Accordingly, the use of compound, complex, and compound-complex forms are used. Figure 3 shows the number of types of sentence used in the text.

Figure 3. Total Number of Types of Sentence Used

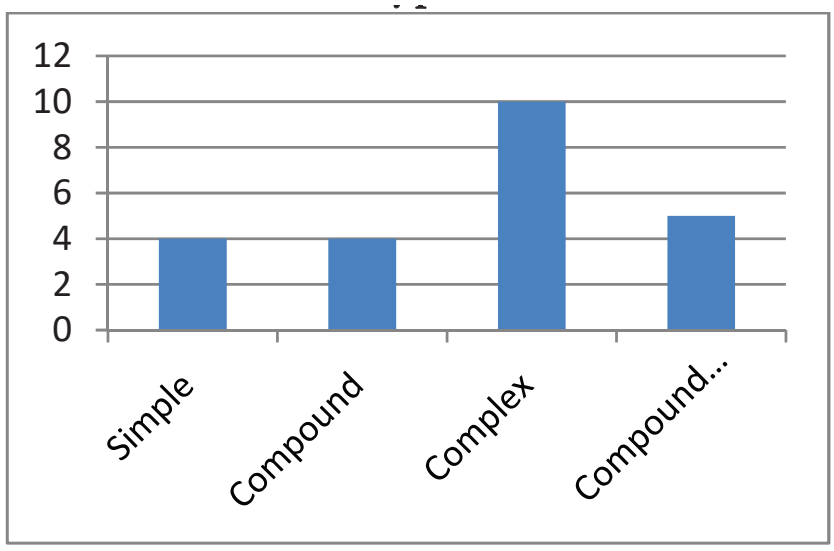

Related to formality of the text, formal language is used in the text. This is to signify that the author, the readers, and the participants both pros and opponents are scientific and educated people (Kristina, 2011). The example of formal language used in the text is moral controversy around whether using computer like tablet for teenagers bring more advantages than drawbacks has swelled over the past several years.

To show the formality and intellectuality of the text, the author put evident-based reasoning in every argument. To exemplify some are (1) not to mention most of developed countries prohibit children to use computers and intrigue them to play in so-called real life; (2) In a Canadian study, children were found to 
have more technology abuse than teenagers; and (3) In New Jersey, which has strictly supervised the use of computer for children wither at home or school, it is estimated that hundreds of lives are being mentally "saved" every year. Scientific argument is mostly scaffold by the existence of evident-based analysis in order to reveal the writer does not tell the author a lie. This is common and important in either spoken or written form of discussion.

\section{Expressive Value}

Expressive value is related to the appraisal (Flowerdew, 2013). The text uses many expressive values to soften or sharpen the evaluation to children as the object of this text. Irresponsible, less mature, lack of experience are language evidence to show and portray the attitude of children. The author uses the words as justifiable reasons why should and why should not allow children to play with computer. On the other hand, would, will, and to prove signify that no pressure from the author to follow one of the two. The author is, in conclusion, not authoritative. $\mathrm{He} / \mathrm{she}$ is an open-minded and democratic person who welcomes all arguments so long as the argument is logic, plausible, and evident-based. It is in line with Miasari, Arsyad, and Arono (2018) that expressive values by using adjectives are frequently used to stress of the judgment and it is to state the importance of the field.

\section{Textual Structure}

The interactional convention which is used is varied in to two: logical orientation and contradictory orientation. The logical orientation shows that this is an inter-side orientation. The author builds each side (affirmative and negative) argument logically. It is plausible because the author struggles to provide the readers logics of why or why not, and should or should not. To make all arguments sound logic, the author provides proposals and why proposals should be proposed. On the other hand, contradictory orientation shows that this is an orientation between positive and negative sides who contradict each other. The language evidences are in contrast, vice versa, contradicts, and so on. Beyond its structure, this text is about the maturity and responsibility in using computer. The text portrays what is exactly happening in daily life. Many children are allowed to use computer. Many others are not. Whether or not they should be allowed, the author provides argument to why this less mature, not ready, and irresponsible in using computers type of person is based on logic. The contention lies on the cause; is it true that maturity and responsibility are the main factors of the technology abuse especially in using computer? If yes, is to postpone them to use computer until teenagers considered effective? What about allowing by supervising them? Does it sound more acceptable?

On the other hand, this text also shows intertextuality where the data are provided through other resources which support the arguments. It means that the author uses other texts to complete his/her text. It is very important prominently for discussion text because the existence of evidence is extremely needed and way to find out the evidence is by employing other related texts. 


\section{Interpretation}

The second sub-heading is called interpretation. Interpretation is context of situation which consists of (1) field which is defined as what is going on; (2) tenor understood as who is involved in the interaction; and (3) mode that concern with ways or medium in the interaction. The three elements are called situational context.

Field refers to social activity, and topic/content of the test (Santosa, 2011). Analysis of the text shows that the social activity of the text is institutionalized. It means that the activity is conducted by the rules of the institution. It can be shown by the structures of the text which obey the rules of making a discussion text. Institutionalizing the activity is aimed at struggling to show the cultural value of the text. By value, it refers to content of the text which is related with education. The value of education can be seen from the way the author inserts the value of responsibility, maturity, and engagement. On the other hand, semantic domain of the text is unspecialized because the author is not the expert of law or part of computer force or psychologist. It can be known from the diction in which disciplinary knowledge is absent. Disciplinary knowledge is only produced by those who are actively involved within discourse community (Knapp \& Watkins, 2005). It is because the readers are average people who have limited capacity to understand technical words.

Tenor refers to formality, status or power, affection, and contact (Halliday and Hasan, 1985). This is also about who is positioned as agent, someone that becomes subject of the sentence, and in what way (Warburton, 2016). Firstly, in terms of formality, the text is situated in formal condition where procedures of interaction are predetermined. It can be seen from the generic structure of the text which is structured well. They are statement of issue, argument for, argument against, and summary. This structured paragraph is called genre or cultural context of discussion text. Secondly, the status or power of the author to the reader is equal. It is shown through the chosen modality choices, will, and would, which have the capacity to suggest and influence not to instruct instead, as well as the absence of imperative sentence. It is intentionally written such a way as an effort to position the readers equal to the author because the aim of the author is just to discuss the issue. On the other hand, the arousal in emotional aspect is ideational instead of interpersonal. It can be seen from the content which is full of academic content. This is the way the author struggles to show the scientific arguments to reach the trustworthiness because the participants are two educated factions. Finally, the frequency of the contact is rare because the choice of words is formal. This is to maintain the scientific nuance of the text.

Mode is way or medium of interaction which consists of planning, distance, and channel (Santosa, 2011). The interaction in the text is previously planned to make the harmony of the text exists so the readers can understand more easily. On the other hand, no feedback is given to the author directly because the author is not reachable by the readers. From the characteristics of the text, the channel is written text as explained as written text is characterized by the use of formal, complex, and abstract choices of language (Saragih, 2011). 


\section{Explanation}

The author is not in the capacity to instruct the readers to follow his/her choice. The author is in the capacity of giving scientific and analytical arguments about the issue. He is also in the capacity to overcome diversity in arguing by giving balanced pro and against arguments to the issue. It is supported by Hidayati (2017) that conducting a free discussion can overcome different background of people to be put together to adjust and adapt to each other. However, there is a tendency shown by the author in the last paragraph. He/she prefers to allow children to use computers under supervision or control of their parents as the way they learn responsibility and being mature naturally. Above all, this text is about technology and children. The reason why the author prefers to support the use of computers for children is because she/he has motives to support or also probably because the author is just an openminded, critical, scientific and logic person and his/ her decision comes from his/her deepest thought without any intervention from others.

\section{CONCLUSION}

Criticizing socio-cultural and ideological values hidden in a text enables the readers to broader information rather than what language structure of the text offers. By using Fairclough's staging analyses, the text used as the object to this study reveals some extensions. They are (1) the language used in the text is dominated by the language used in the text is dominated by formal diction, complex sentence, verbal process, some repetitive words, multi-perspective arguments, evident-based complex sentences, metaphorical technique, and over- wording dictions underpinned in an institutionalized social activity and unspecialized semantic domain. From the language structures, socio-cultural context analyses, it is also found that (2) its power to the readers is equal that the author provided, rather than provoked, scientific and analytical arguments about whether children should be allowed to use computer. This is in line with the nature of discussion text as a text providing multi-perspective arguments instead of standing on particular party.

\section{REFERENCES}

Bloor, Thomas \& Bloor, Meriel. (2004). The functional analysis of English. London: Oxford University Press.

Bukhari, Nasir H. S. \& Xiaoyang, Wang. (2013). Critical discourse analysis and educational research. IOSR Journal of Research \& Method in Education, 3(1), 9-17.

Fairclough, Norman. (1989). Language and power. New York: Longman.

Fairclough, Norman. (1995). Critical discourse analysis: The critical study of language. New York: Longman.

Flowerdew, John. (2013). Discourse in English language education. London: Routledge.

Halliday. M. A. K., \& Hasan, R. (1985). Language, context, and text: Aspects of language in a social-semiotic perspective. Viktoria: Deakin University Press.

Hidayati, Nani. (2017). Appraisal analysis in freedom writers movie. EDULITE Journal of English Education, Literature, and Culture, 2(1), 317-333.

Jiao, Jian \& Zhou, Yanquan. (2011). Sentiment polarity analysis based multi-dictionary. Retrieved June 42019 from http://www.researchgate.net/ publication/257706726-Sentiment-Polarity_ Analysis_Based_Multi-Dictionary

Knapp, Peter \& Watkins, Megan. (2005). Genre, text, grammar. New South Wales: UNSW Press.

\section{4}


Kristina, Diah. (2011). Discourse analysis. Surakarta: UNS Press.

Leech, G. (2000). Grammars of spoken English: New outcomes of corpus-oriented research. Language and Learning, 8(3), 675-728.

Locke, Terry. (2004). Critical discourse analysis. London: Continuum.

Lukin, Annabelle. (2017). Ideology and the text-incontext relation. Journal of Functional Linguistics $4(16), 1-17$.

McCarty, M. \& Carter, R. (2001). Ten Criteria for Spoken Grammar. New Perspectives on Grammar Teaching in Second Language Classroom, 2 (3), 51-75.

Miasari, Suci., Arsyad, Safnil, \& Arono. (2018). Indonesian authors' stances in citing English research article introductions literature in sciences. EDULITE Journal of English Education, Literature, and Culture. $3(2) .173-187$.

Nasution, Sukma Septian. (2018). The mass media's language styles: Its power and appropriateness from the perspectives of systemic functional linguistics. Premise: Journal of English Education and Applied Linguistics 4(1), 124-134.

Priatmoko, Nova Anggit. (2013). Critical discourse analysis of Susilo Bambang Yudhoyono speech. (Unpublished Thesis). Universitas Dian Nuswantoro: Semarang.

Rambe, Patient. (2012). Critical discourse analysis of collaborative engagement in Facebook posting. Australation Journal of Educational Technology. 28(2), 295-314.
Rahmah. (2011). Systemic functional grammar. Medan: Unimed Press.

Santosa, Ryadi. (2011). Logika wacana. Surakarta: UNS Press.

Saragih, Amrin. (2011). Semiotik bahasa: Tanda, penanda, dan petanda dalam bahasa. Medan: Unimed Press.

Syarifah, Eva Fitriani \& Gunawan, Wawan. (2015). Scaffolding in the teaching of writing discussion text based on sfl-genre based approach. English Review: Journal of English Education, 4(1), 39-53.

Van Dijk, T.A. (2008). Discourse and context: A sociocognitive approach. Cambridge: Cambridge University Press.

Warburton, Trevor. (2016). Turning the lens: Reflexivity in research \& teaching with critical discourse analysis. Journal of Critical Questions in Education, 7(3), 249-267.

Thomson, Stefan. (2007). Differing opinions: A critical discourse analysis of two articles. (Unpublihed Dissertation). University of Birmingham: Birmingham.

Trabelsi, Amine, \& Zaiane, Osmar R. (2014). Finding arguing expressions of divergent viewpoints in online debates. Retrieved June 42019 from https://www. aclweb/anthology/papers/W/W14/W14-1305/ 